\title{
The Impact of Reputation, Costs, and Interactive Care on Patient Satisfaction
}

Wu Lu ( $\sim$ Luwu@zucc.edu.cn )

Zhejiang University City College https://orcid.org/0000-0003-3303-5069

Latif Al-Hakim

University of Southern Queensland

\section{Research article}

Keywords: Common method bias, costs system, hospital reputation, treatment, mediation, Moderation.

Posted Date: November 30th, 2020

DOI: https://doi.org/10.21203/rs.3.rs-109605/v1

License: (ㅇ) This work is licensed under a Creative Commons Attribution 4.0 International License. Read Full License 


\section{Abstract}

Background. This research empirically tested the impact of hospital reputation and its cost system on the relationship between hospital's interactive care and patient satisfaction.

Methods. An anonymous, self-administrated questionnaire was distributed randomly among outpatients in five large hospitals located at Zhejiang Province, China. Controlled common method bias test was conducted to ensure that the common variance is not a major concern in data analysis. One-factor congeneric measurement was employed to test fitness of factors assigned to variables. Data were further tested for convergence validity, and internal and item reliability. SPSS v.25 software with PROCESS v.3.3 model in a bootstrap approach were used to test the mediation and moderation effects.

Results. We received 1441 valid responses (valid response rate $66.6 \%$ ). A total of 22 questionnaire items out of 25 items survived the factor analysis and common method bias tests. Results show significant positive correlation $(\rho<0.01)$ between the model's variables, with correlation between interactive care and reputation (0.732) is the highest. The analysis indicates the hospital reputation moderates the relationship between hospital's reputation and patient satisfaction. It also illustrates that poor payment administration may affect the patient satisfaction, but its effect is much less on the hospital's reputation.

Conclusion: This research validates two assertions of other research works. First, hospital reputation is more important factor than costs in the selection of the hospital, and second, the perception that healthcare providers with higher expenses provide better care are not true always. Further, our research gives a reason as why many patients from rural area usually manage appointments with doctors in hospitals in urban area rather than having appointment with doctor in the Rural Community hospitals, which have lower reputation.

\section{Summary}

A growing line of research indicates a positive relationship between hospital reputation, costs and patient satisfaction. This research empirically tested the roles of hospital reputation and its cost system on the relationship between hospital's interactive care and patient satisfaction. The study sample consisted outpatients of five hospitals located at Zhejiang Province, China. Results indicate that the hospital reputation moderates the relationship between hospital's reputation and patient satisfaction. It also illustrates that poor payment administration may affect the patient satisfaction, but its effect is much less on the hospital's reputation. Our research shows that patients depend highly on data available in social media in their perception on hospital reputation. This research validates two assertions of other research works. First, hospital reputation is more important factor than costs in the selection of the hospital, and second, the perception that healthcare providers with higher expenses provide better care are not true always. Further, our research gives a reason as why many patients from rural area usually manage appointments with doctors in hospitals in urban area rather than having appointment with doctor in the Rural Community hospitals, which have lower reputation.

\section{Background}

Patient satisfaction is increasingly recognized as an important research area that significantly affect the hospital reputations and ultimately, affect the hospital revenue [1;2; 3]. Literature emphasizes the positive relationships between patient's satisfaction and quality of technical services, (medical treatment). they received [4;5;6; 7]. Satisfaction is a necessary element that motivates patients to accept the treatment, follow medical instructions and then accelerate health recovery $[2 ; 8]$.

Satisfaction also influences the behavioural intention of patients. Satisfied patients are more likely to be loyal to their hospitals and recommend the hospital to other patients, friends and families $[9 ; 10 ; 11]$. From this perspective, hospital management looks to positive patient's behavioural intention as the ultimate aim from satisfying their patients [12]. In this research we consider both patient satisfaction and patient behavioural intention.

Despite the obvious correlation between satisfaction and treatment, patients may have no adequate education on medicine and the question arises as to whether patients can provide valid and reliable evaluation of the clinical treatment [13]. However, there are other domains allowing patients to evaluate indirectly the hospital technical services, including interactive care, (interaction between patients and technical healthcare providers), Administrative aspects, and the environment within which the treatment is provided [14; $15 ; 16]$. Administrative and environmental aspects comprise a wide range of managerial activities that facilitate the delivery of 
services. This research considers interactive care and the functional elements of administrative and environment aspects that are directly associated with, or facilitate the interactive care.

The reputation of an organisation reflects the perception of organisation's customers, employees, and the general public [17]. Literature points out to hospital reputation as a variable influencing hospital selection and affecting patient satisfaction $[18 ; 19 ; 20]$. Jung et al. [21] show that perceptions related to a hospital's reputation plays major role in the selection of the hospital. Abd-El-Salam et al. [22] state that hospital reputation is correlated with service quality and customer satisfaction.

Another area affecting the patient satisfaction is the hospital costs or billing system [23]. Healthcare costs system is one of the patient's consideration in selecting a hospital [24]. Studies shows that higher expensive hospitals are perceived by patients to provide better healthcare [3; 25]. Limited research indicates correlation between satisfaction and behavioural intention, reputation, and costs $[24 ; 26]$. From research point of view, correlation between variables is a necessary condition indicating potential role of a variable on its relationships with other variables. However, correlations don't show the type and magnitude of the variable's role. That is, whether a variable mediates or moderates relationships of other variables. According to our best knowledge, the roles of hospital reputation and costs on the relationships between interactive care and patient satisfaction and behavioural intention have not been investigated in the current literature. Our research is an attempt to fill this gap in literature. It considered four large teaching hospitals located at Zhejiang Province in China as a case. A questionnaire was designed and distributed among 1441patients. SPSS, AMOS software and PROCESS tool [27] was used to analyse data.

\section{Literature review}

The effect of service quality on patient satisfaction has been widely researched in the literature $[2 ; 8 ; 22 ; 28]$. There are several approaches for defining service quality. Grönroos [29] considers the work of Swan and Combs [30] and express the concept of service quality into two dimensions; technical dimension (knowledge and skills) and functional dimension (interaction between customer and service provider). Parasuraman et al. [31] proposed two service quality dimensions, namely 'outcome' and 'process' which correspond to the the dichotomy proposed by Grönroos [29]. Another service quality model is known as SERVQUAL [32]. It defines the quality into five dimensions; tangibles, reliability, responsiveness, assurance, and empathy [32]. Mangold and Babakus [33] classify service quality into two stages; front-stage, and back-stage. The former refers to the interaction of customer with the service provider and the later considers interactions with the other service activities [34].

Glushko and Tabas [34] distinguish between the interactions of the customer and provider that are part of the service encounters (or front-stage activities) and other activities that precede those encounters (back-stage activities) and make them possible. Glushko and Tabas stress that the focus in the service quality is on the interaction between employees and customers, and the service quality is mainly determined during the final "service encounters" that takes place in the front stage. According to Parasuraman et al. [35] these encounters are the service from the customer's viewpoint. Mangold and Babakus [33] emphasise that service providers' back-stage perspective may limit their ability to understand customers' expectations, because "the customer has a front-stage perspective, he is usually unaware of many of the activities and problems that occur behind the scene". Based on the above argument, the technical and functional dimensions of service quality proposed by Grönroos [29] are within the concept of front-stage service quality.

\section{Interactive care}

The technical and functional dimensions of service quality are applicable to healthcare services as they directly relate to the treatment, determine the correct diagnosis and satisfy patient needs for comfort and safety $[14 ; 15 ; 36 ; 37]$. Some adaptation, however, is necessary, mainly because the patient is a customer as well as the subject matter for services, in which the treatment is directly related to the patient's wellbeing. Patients are trying to search for information from social media, family, friend, and other patients. The rapid evolution of Internet facilitates such search and change the way medical practitioners communicate and educate themselves and their patients [38]. This gives patients general knowledge on the technical service, but such knowledge does not mean that patients have adequate education and ability to evaluate the technical dimensions of the clinical services they received. However, patients may no longer ready to accept treatments, especially for serious illness, without clear and convincing explanation from the medical professionals. Ong et al. [39] review the literature and assert that physicians' information provision has been significantly related to patient satisfaction. It follows that physician-patient interaction plays major role in creating patient satisfaction [14; 40; 41]. Jacobs et al. [26] recognize physician-patient interaction to be of diagnostic import and therapeutic benefit. Dagger et al. [42] widen physician-patient concept to interactive care which is a reference to the care provided by any professional 
staff (physician, nurses, pharmacist, etc.) of the service provider. Gupta et al. [8] find that patient satisfaction with interactive care they receive is a predictor of survival in server illness such as breast cancer. Interactive care encourages patients for more engagement in their healthcare [43; 44] which, in turn, enhances patient satisfaction [8; 42; 45].

In addition to interactive care, Ware et al. [16] add two additional elements to the functional dimension of the service quality. These elements are administrative aspects and environment aspects. McDougall an Levesque [46] suggest an element referred to as 'enablers' which is analogous to administrative aspects. Environment element represents the general features that shape the patient services perceptions [42; 47].

Patients interact and influence with services that are delivered (front-stage activities) rather than managerial activities administrating the delivery of services (back-stage activities). In addition, our study was taken in China and considering the major public hospitals at Zhejiang Province. These hospitals are governed by the same local government of Zhejiang Province and have similar physical appearance and environment. This make the apparent physical environment aspects of these hospitals are less effective in the patients' selection and their satisfaction. Unlike other research works [32; 42; 48; 49], this research considers the functional elements of administrative and environment aspects that are directly associated with the interactive care. That is, activities patient experienced inside the examination rooms and wards where the interactive care with professional staff take place, including privacy during diagnosis and telephone and staff interruptions at the time of patient's examination.

\section{Patient satisfaction and behavioural intention}

Much of marketing literature looks to the satisfaction as the meeting of customer expectation with the perceived performance [32; 50]. Rust and Oliver [51] describe consumer satisfaction as the degree to which the consumer believes that provider services educe the positive feelings. On other words, satisfaction reflects the consumer royalty and influences his/her behavioural intention and retention [52]. Recent research works consider patient satisfaction from the royalty and behavioural intention perspective [9; $12 ; 52$; 53]. Healthcare literature points out to the interpersonal relationship or interaction between patients and healthcare providers as the most important factor of customer satisfaction [1; 14]. As early as 1996, Zeithaml et al. [54] associate behavioural intention with saying positive things about service providers, recommend the services to families and other friends, and royalty. So it is important to associate patients' satisfaction with behavioural intention to reflect the degree of association of the consumer satisfaction, or feelings, with the service providers [12; 52]. For simplicity, we use the term 'patient satisfaction' to reflect both satisfaction and behavioural intention of the patients.

\section{Research hypotheses}

Considering the above argument, we predict the following hypothesis.

\section{Hypothesis}

$(a-c)$ : Patient satisfaction will be positively and directly influenced by; (a) interactive care, (b) reputation, and (c) costs.

The positive effect of reputation on both healthcare and satisfaction leads us to hold that the effect of interactive care on satisfaction can better be explained through reputation. Accordingly, we propose the following hypothesis (Fig. 1A):

\section{Hypothesis 2}

The hospital's reputation will mediate the relationship between interactive care and patient satisfaction.

Literature refers to the cost of healthcare as major factor influencing the patient's selection of healthcare organisation as well as their satisfaction [23; $24 ; 55]$. Several studies indicate healthcare providers with higher expenses are perceived by patients to provide better care [24]. Low-income families, however, may use hospitals associated with lower costs [56]. On the other hands, DiCenzo and Freedman [57], examine the costs of healthcare providers in Massachusetts and stress that the highest paid providers do not necessarily provide the highest quality of care. DiCenzo and Freedman stress that provider price, not utilization of health care services, remains the biggest health care cost driver and administrative costs can burden the system and impede transparency [57]. In this regard, Baji et al. [58] stress that to assure the costs acceptance, hospitals should provide real improvement on care noticeable for patients. Satisfied patient improve physician satisfaction and then functional quality $[59 ; 60]$ which, in turn, improve interactive quality. Kenagy et al. [61] show that poor services usually comprise wasted effort and materials and, accordingly, significant 
reduction in the costs could be achieved with improved services. This argument may suggest that healthcare costs may specify conditions under which the healthcare relate to satisfaction. We hypothesise the following relationship (Fig. 1B):

\section{Hypothesis 3}

Hospital costs will moderate relationship between interactive care and satisfaction.

White et al. [62] stress that the differences between low - and high - costs hospitals are their size and market share. Much researcher works associate hospital costs with care and reputation, and hospital cost with reputation and patient satisfaction patient $[21 ; 24 ; 63 ; 64]$. This suggest that costs may moderates the relationships between care and reputation as well as between reputation and satisfaction (See Fig. 1C):

\section{Hypothesis 4}

Hospital costs will moderate relationship between interactive care and reputation.

\section{Hypothesis 5}

Hospital costs will moderate relationship between reputation and patient satisfaction.

We may also suggest the following hypothesis (Fig. 1C):

\section{Hypothesis 6}

In presence of reputation, the hospital costs will stay moderating the relationship between interactive care and reputation.

the validity of hypotheses 4 to 6 depends on the strength and effect of reputation relative to costs. For instance, in case that reputation strongly influences the relationship between integrative care and satisfaction much more than the effect of costs, the correlation between integrative care and satisfaction will stay insignificant in presence of both reputation and costs. In such situation, hypothesis 6 will not be satisfied.

\section{Methods}

Our methodology comprises three stages; preparation stage, data collection stage and data analysis stage

\section{Preparation stage}

Before the start of the research, ethical approval was obtained from the Research Office of the Zhejiang University City College, Hangzhou, China. Ethical approvals also were obtained from the Research Review Board of the participating hospitals. Consent of respondent's participation was implied by agreeing and completion of the research instrument. Patients participating in the survey were ensured that the anonymity of the respondents was maintained on the questionnaire or any other research document stems from their responses.

\section{Preparing the questionnaire}

First, list of factors was established from the related literature and discussed with three medical doctors and four nurses. The list was revised and modified, and initial questionnaire was created. Second, a pilot study was conducted in which 40 patients from two hospitals (20 patients from each), were interviewed, requested to fill the questionnaire and provide their suggestions. The result of the pilot study was the development of the survey questionnaire.

The questionnaire comprises three parts. The first part deals with demographics data. The second part includes 25 items related to patient satisfaction ( 7 items), integrative care (8 items), costs / payment system ( 5 items) and hospital reputations (5 items). Table 1 shows the items and the sources from which these items were adopted. The patients are requested to evaluate each item using 5point Likert scale, in which five represents the 'strongly agree' with the statement of the item and one indicates 'strongly disagree' with the item's statements. The last part of the questionnaire comprises an open-ended question allowing the patient to specify suggestions. 
Table 1

Model variables, statements for associated items (factors), factor code, and references

\begin{tabular}{|c|c|c|c|c|}
\hline No. & Variable & Item statement & Code & Reference \\
\hline 1 & \multirow{7}{*}{$\begin{array}{l}\text { Patient } \\
\text { Satisfaction }\end{array}$} & I am satisfied with the quality of treatment at this hospital & SAT1 & \multirow{3}{*}{$\begin{array}{l}\text { Parasuraman, et } \\
\text { al., 1988; } \\
\text { Olive \& Rust, } \\
\text { 1994; }\end{array}$} \\
\hline 2 & & I believe the results of my treatment will be best they can be & SAT2 & \\
\hline 3 & & I believe having treatment at this hospital has been worthwhile & SAT3 & \\
\hline 4 & & I will recommend the hospital to my family, friends and other patients & SAT4 & $\begin{array}{l}\text { Cronin, et al., } \\
\text { 2000; }\end{array}$ \\
\hline 5 & & I will say positive things about the hospital & SAT5 & \multirow{3}{*}{$\begin{array}{l}\text { Gill \&White, } \\
\text { 2009; } \\
\text { Jalil, et al., 2017; } \\
\text { Amin \& Zahora, } \\
2013\end{array}$} \\
\hline 6 & & I intend to follow medical advice given to me at this hospital & SAT6 & \\
\hline 7 & & $\begin{array}{l}\text { I have no desire to change the hospital and will come again to this hospital } \\
\text { when needed }\end{array}$ & SAT7 & \\
\hline 8 & \multirow[t]{11}{*}{$\begin{array}{l}\text { Integrative } \\
\text { care }\end{array}$} & The doctor at this hospital listen calmly to what I have to say & INT1 & \multirow{6}{*}{$\begin{array}{l}\text { Taub, 2006; } \\
\text { Ong, et al.,1995; } \\
\text { Ruusuvuori, } \\
\text { 2001; } \\
\text { Dhaliwal \& Hunt, } \\
\text { 2004; } \\
\text { Jalil, et al., 2017; } \\
\text { Jacobs, et al., } \\
\text { 2007; } \\
\text { Dagger, et al., } \\
\text { 2007; } \\
\text { Drenkard, et } \\
\text { al.,2015; }\end{array}$} \\
\hline 9 & & I feel that the doctor treats me as an individual and not as a number & INT2 & \\
\hline 10 & & $\begin{array}{l}\text { I find it easy and convenience to discuss my illness and treatment with the } \\
\text { doctor at this hospital }\end{array}$ & INT3 & \\
\hline & & & & \\
\hline 11 & & $\begin{array}{l}\text { The doctor at this hospital explains my illness, and the treatment in a way } \\
\text { that I can understand }\end{array}$ & INT4 & \\
\hline 12 & & The doctor is willing to answer adequately all my questions & INT5 & \\
\hline & & & & \multirow{5}{*}{$\begin{array}{l}\text { Wong, et } \\
\text { al.,2012; } \\
\text { Krouse } \\
\text { \&Roberts, 1989; } \\
\text { McDougall \& } \\
\text { Levesque,1995; } \\
\text { Gotlieb, et } \\
\text { al.,1994; } \\
\text { Mosadeghrad, } \\
\text { 2014; } \\
\text { Curry \& Sinclair, } \\
\text { 2002; }\end{array}$} \\
\hline 13 & & $\begin{array}{l}\text { I feel the doctor at this hospital is concerned about my privacy during } \\
\text { diagnosis }\end{array}$ & INT6 & \\
\hline & & & & \\
\hline 14 & & $\begin{array}{l}\text { I feel the doctor does not allowed interferences from nurses or other staff } \\
\text { during my diagnosis }\end{array}$ & INT7 & \\
\hline 15 & & I feel the doctor avoids answering telephone calls during my diagnosis & INT8 & \\
\hline 16 & \multirow[t]{5}{*}{ Reputation } & $\begin{array}{l}\text { I believe the medical staff at the hospital are confidence and have good } \\
\text { professional reputation }\end{array}$ & REP1 & $\begin{array}{l}\text { Mira \& Lorenzo, } \\
\text { 2014; }\end{array}$ \\
\hline 17 & & $\begin{array}{l}\text { The published materials by the hospital give impression of the hospital's } \\
\text { good reputation }\end{array}$ & REP2 & $\begin{array}{l}\text { Dijs-Elsinga, et } \\
\text { al., 2010; }\end{array}$ \\
\hline 18 & & The hospital reputation is perceived high in social media (e.g., WECHAT) & REP3 & \multirow{3}{*}{$\begin{array}{l}\text { Sehgal, 2010; } \\
\text { Pilny \& } \\
\text { Mennicken, } \\
\text { 2014; }\end{array}$} \\
\hline 19 & & The hospital ranks high by the government & REP4 & \\
\hline & & & & \\
\hline
\end{tabular}




\begin{tabular}{|c|c|c|c|c|}
\hline No. & Variable & Item statement & Code & $\begin{array}{l}\text { Abf-EI-Salam, e } \\
\text { âefênce }\end{array}$ \\
\hline 20 & & $\begin{array}{l}\text { The hospital's involvement and sponsorship of social and cultural activities } \\
\text { significantly enhance its reputation }\end{array}$ & REP5 & \multirow{3}{*}{$\begin{array}{l}\text { Jacobsen, et al., } \\
\text { 2012; }\end{array}$} \\
\hline 21 & \multirow[t]{6}{*}{ Payment } & The Payment bill is easy to read and understand & PAY1 & \\
\hline 22 & & I believe the payment is adequate in comparison to diagnosis and treatment & PAY2 & \\
\hline 23 & & The bill I received includes details of my diagnosis and treatment & PAY3 & \multirow{2}{*}{$\begin{array}{l}\text { Siddiqui \& } \\
\text { Khandaker, } \\
\text { 2007; } \\
\text { Nelson, et al., } \\
\text { 1994; }\end{array}$} \\
\hline 24 & & $\begin{array}{l}\text { The hospital staff explain to me what I need to do if I am having trouble } \\
\text { paying medical bill }\end{array}$ & PAY4 & \\
\hline \multirow[t]{2}{*}{25} & & $\begin{array}{l}\text { The hospital staff are courteous in explaining bill items and answering my } \\
\text { related questions }\end{array}$ & PAY5 & Blizzard, 2004; \\
\hline & & & & $\begin{array}{l}\text { Jacobs, et al. } \\
2007\end{array}$ \\
\hline
\end{tabular}

\section{Data collection}

The distribution of questionnaire and data collection were managed during march - December 2018. Each participating hospital assigned liaison officer to help the first author and two of her students (data collection team) in contacting patients and distribution and collecting the questionnaire. At the start, the team explained to the patients the objective of the questionnaire and assure them of anonymity. Usually, the responses were collected in the same day or followed by WECHAT app - the popular social media which usually used by most Chinese citizens. Microsoft Excel spreadsheet file is created for data collection and SPSS 25 software was used to scrutinise data. Maximum Likelihood Estimate available in SPSS was used to estimate the missing data.

\section{Data analysis}

This stage explains methods used for testing model fitness, testing validity and reliability, and testing mediation and moderation relationships

\section{Testing model fitness}

Service quality models are best conceptualised as formative in which factors assigned to a construct give rise to or cause the construct [ $42 ; 65]$. This one-factor congeneric measurement is an appropriate technique as it is used to test fitness of factors assigned to each construct $[66 ; 67 ; 68]$. AMOS v.25 is employed to check the fitness of the model constructs, with the following threshold level; Nominal Chi-square $\left(\chi^{2} / \mathrm{df}\right) \leq 2$, Overall probability level $>0.05$, Standard Regression Weight $(\mathrm{SRW}) \geq 0.05$. Root Mean Square Error of Approximation (RMSEA) $<0.07$, Root Mean Square (RMR) $<0.01$, P of close fit $\geq 0.05$, Goodness-of-Fit (GFI) and Adjusted Goodness-of-Fit (AGFI) $\geq 0.90$, and Cronbach's Alpha (a) $>0.70[69 ; 70]$. It should be noticed that SRW is a reference to factor loading and each factor with SRW less than .50 will be deleted.

\section{Testing measurement errors and data distribution}

This work is an empirical research that relies on self-report measurements for data gathering which might contribute to common method bias. Common method variance is the observation of such bias, which attributed to the measurement method rather than to the research variables [71]. The impact of such bias may affect the actual relationship between the model's variables and might be contaminated by shared variance associated due to several reason, including respondent's consistency, mood states, and item similarity and social desirability [72]. We follow the recommendation of Podsakoff et al. [73] and select unmeasured latent method factor technique. This technique allows us to report that common method bias is not a major concern in our analysis where the percentage of the variance below the average amount of method variance $(25 \%)$ for survived items of the questionnaire. It has advantage to test the normality of the data distribution. Kurtosis and skewness test can be used to test the normality [74; 75], with acceptable range of Z-values for both skewness and kurtosis between -1.96 and +1.96 [76]. The analysis facility of SPSS can be used to measure the kurtosis and skewness of independent factors and the z-value can be calculated by dividing the skewness of kurtosis values by their associated standard errors.

\section{Testing Validity and Reliability}


Convergence validity is achieved with factor loading (standard regression weight 'SRW') equal or exceeding 0.50 . A factor with loading of less than 0.50 should be removed. The squared multiple correlation (SMC), and Cronbach's alpha if an item is deleted ( $\left.a_{d}\right)$ is used to measures item reliability. The SMC value exceeding 0.5 indicates a good reliability; and above 0.3 indicates an acceptable item reliability. The value of $a_{d}$ for each factor should be more than 0.7 . The value of construct Cronbach's alpha is $\geq 70$ for good internal reliability $[69 ; 77]$.

\section{Testing Moderation and Mediation Effects}

PROCESS v.3.3 tool developed by Hayes [27; 78] was used to test the mediation and moderation effects as stated in the study's hypotheses. The PROCESS model is an add-on of SPSS. The ANALYSIS function of SPSS was used to determine the correlation and regression analysis for the components of the model.

In testing a casual process involving a mediation component, the mediation effect was determined using bootstrap facility and determining the total direct effect, the direct effect and indirect effect. For bootstrapping approach, the model should be significant with significant $\mathrm{R}^{2}$ and the total Direct effect between outcome and predictor variable in presence of mediator should be insignificant, or less significantly than total direct effect without the mediator. The indirect effect should be significant and statistically different from zero. That is, the bootstrap confidence interval (ULCl - LLCl) essentially does not contain zero.

For the determinisation of moderation effect of a variable using PROCESS tool, the model should be significant with significant $\mathrm{R}^{2}$ and the interaction between predictor variable and the moderator should be significant and statistically different from zero. That is, the bootstrap confidence interval (ULCI - LLCI) essentially does not contain zero. Excel can be used to plot the effect of moderator on the outcome of the model.

\section{Results}

A total of around 2000 questionnaire were distributed randomly among patients from four large teaching hospital allocated in three cities at Zhejiang Province, China. We received 1509 responses, among them 1441 responses were considered valid, (valid response rate $66.6 \%$ ). Table 2 depicts the demographic data of the patient participants. The table shows that a total of 815 patient participants were female (56.6/\%), and 626 were male (43.4\%). Most of the participants (917) were living in urban area (63.6) with only 524 (36.4\%) were came from rural areas. The age of majority of the participants (76.9\%) was less than 50 years, among them 107 participants $(7.5 \%)$ with ages range from 18 years. Most of the participants ( 1034 forming $71.8 \%$ of the respondents) were visited the hospital more than once (Table 2). Table 2 also shows that a total of 1124 participants (84.9\%) had education higher than primary school. Usually, the responses for immature patients were filled by their parents or companions. 
Table 2

Demographic data for respondents

\begin{tabular}{|c|c|c|c|}
\hline Variable & Detail & Number & Percent \% \\
\hline \multirow[t]{2}{*}{ Gender } & Male & 626 & 43.4 \\
\hline & Female & 815 & 56.6 \\
\hline \multirow[t]{5}{*}{ Age } & Less than 18 years & 107 & 7.5 \\
\hline & 18 to less than 30 years & 478 & 33.2 \\
\hline & 30 to less than 50 years & 523 & 36.3 \\
\hline & 50 to 60 years & 146 & 10.1 \\
\hline & 60 years and above & 187 & 13.0 \\
\hline \multirow[t]{3}{*}{ Number of visiting the hospital } & First time & 407 & 28.2 \\
\hline & 2-3 times & 543 & 37.7 \\
\hline & 4 and more & 491 & 34.1 \\
\hline \multirow[t]{3}{*}{ Education } & Primary school & 217 & 15.1 \\
\hline & Secondary of higher school & 800 & 55.5 \\
\hline & University level & 424 & 29.4 \\
\hline \multirow[t]{2}{*}{ Living area } & Urban area & 917 & 63.6 \\
\hline & Rural area & 524 & 36.4 \\
\hline \multirow[t]{2}{*}{ Insurance } & Without insurance & 587 & 40.1 \\
\hline & Insured & 854 & 59.3 \\
\hline \multirow[t]{3}{*}{ Self-assessment of illness } & Serious illness & 426 & 29.6 \\
\hline & Medium level illness & 773 & 53.6 \\
\hline & Light illness & 242 & 16.8 \\
\hline
\end{tabular}

\section{Testing data errors and normality}

Table 3 illustrates the results of common method bias test. Figure 2 (A, B) shows the graphical outcome for the test using AMOS v.24. The results (Table 3 ) indicates that all factors survived the test have a common method variance less than $10 \%$ (maximum variance is 0.097 or $9.7 \%$ ) which is much below the average amount of average common method variance of $20 \%$ requesting for self-reported research. Accordingly, we can conclude that common method bias does not affect the outcome of our analysis. In addition, the kurtosis and skewness test indicates that all survived factors have z-values for both kurtosis and skewness within the acceptable range of -1.96 and +1.96 . We can conclude, accordingly, that that the distribution of our data are within the acceptable kurtosis and skewness range for normality required for self-report research. 
Table 3

Outcome of common method bias test using latent method factor technique

\begin{tabular}{|c|c|c|c|c|c|c|}
\hline \multirow[t]{2}{*}{ Serial No. } & \multicolumn{3}{|c|}{ Relationships } & \multicolumn{2}{|c|}{ Standard Regression Weight } & \multirow[t]{2}{*}{ Variance } \\
\hline & Code & & Variable & With CLF & No CLF & \\
\hline 1 & SAT7 & $<-$ & Satisfaction & 0.552 & 0.626 & 0.074 \\
\hline 2 & SAT6 & $<-$ & Satisfaction & 0.733 & 0.804 & 0.071 \\
\hline 3 & SAT5 & $<-$ & Satisfaction & 0.678 & 0.748 & 0.070 \\
\hline 4 & SAT4 & $<-$ & Satisfaction & 0.588 & 0.673 & 0.085 \\
\hline 5 & SAT3 & $<-$ & Satisfaction & 0.581 & 0.656 & 0.075 \\
\hline 6 & SAT2 & $<-$ & Satisfaction & 0.600 & 0.697 & 0.097 \\
\hline 7 & SAT1 & $<-$ & Satisfaction & 0.555 & 0.647 & 0.092 \\
\hline 8 & INT6 & $<-$ & Integrative Care & 0.671 & 0.728 & 0.057 \\
\hline 9 & INT5 & $<-$ & Integrative Care & 0.700 & 0.750 & 0.050 \\
\hline 10 & INT4 & $<-$ & Integrative Care & 0.655 & 0.725 & 0.070 \\
\hline 11 & INT3 & $<-$ & Integrative Care & 0.711 & 0.765 & 0.054 \\
\hline 12 & INT2 & $<-$ & Integrative Care & 0.608 & 0.675 & 0.067 \\
\hline 13 & INT1 & $<-$ & Integrative Care & 0.594 & 0.637 & 0.043 \\
\hline 14 & REP5 & $<-$ & Reputation & 0.608 & 0.665 & 0.057 \\
\hline 15 & REP4 & $<-$ & Reputation & 0.634 & 0.683 & 0.049 \\
\hline 16 & REP3 & $<-$ & Reputation & 0.558 & 0.592 & 0.034 \\
\hline 17 & REP1 & $<-$ & Reputation & 0.648 & 0.689 & 0.041 \\
\hline 18 & PAY 5 & $<-$ & Payment & 0.438 & 0.516 & 0.078 \\
\hline 19 & PAY4 & $<-$ & Payment & 0.532 & 0.612 & 0.080 \\
\hline 20 & PAY3 & $<-$ & Payment & 0.855 & 0.878 & 0.023 \\
\hline 21 & PAY2 & $<-$ & Payment & 0.684 & 0.754 & 0.070 \\
\hline 22 & PAY1 & $<-$ & Payment & 0.731 & 0.759 & 0.028 \\
\hline
\end{tabular}

\section{Testing the model fitness, reliability and validity}

The outcome of $\mathrm{KMO}$ test for all items is greater than 0.85 indicating that the data collected are suitable for factor analysis. A total of 22 items out of 25 items were survived the measurement tests and passed the validity and reliability tests. The four variables of the final model were ended with values of Cronbach alpha greater than 0.70, CMIN/DF less than $3, \mathrm{GFI}$ and AGFI greater than 0.8 , and RMSEA less than 0.05 . All indices of the 22 survived items (factors) achieved factor loading (SRW) $>0.5, \rho<0.01$ and ad (Cronbach's alpha if item deleted) $>0.75$ and all other indices are within the threshold limits as indicated in the Methods section. These results evidence of acceptable internal reliability and convergent validity. In addition, this outcome enhances our confidence on the possibility of representing the model variables by averaging the score of survived items belong to each variable (construct) of our model for the purpose of applying PROCESS tool [27].

\section{Testing the mediation effect of reputation}

Table 4 depicts mean, standard deviation and the bivariate correlations between all related variables of the research model, It shows that the three variables, satisfaction, integrative care and reputation, have positive correlations with each other's $(\rho<0.01)$. Based on 
Table 4, hypotheses 1 (a-c) are acceptable. In order to prove hypotheses 2 , we first used regression menu of SPSS to determine any potential moderation for Reputation. Table 5(A) represents the model summary of regression analysis for reputation. It shows the significance of $F$ value change in two models, (1) without interaction, and (2) with interactions. Results indicates the $R^{2}$ change in model 2 for reputation is non-significant $\left(R^{2}=0.000, F(1,1437)=0.076, \rho=0.783\right)$. This result excludes any potential mediation effect for reputation. The outcome of regression analysis allows as to proceed with PROCESS model 4 [27], to test hypothesis 1 in which Reputation is proposed to mediate the effect of Integrative Care on Satisfaction. Table 6 summarises the outcome of implementing PROCESS model 4. It indicates that the value of total direct effect for integrative care on satisfaction is significant $(\rho<$ 0.01 ), direct effect is insignificant $(\rho=0.2141)$, and indirect effect is significant with confidence bands ( $(L C I$, ULCI) do not contain zero $(0.1531,0.2415)$. This outcome signifies that reputation mediates the relationships between integrative care and satisfaction. Hence, hypothesis 2 is acceptable.

Table 4

Mean, STDs, and Pearson correlations among satisfaction, integrative care, reputation and payment

\begin{tabular}{|c|c|c|c|c|c|c|c|c|c|}
\hline & Variable & Mean & STD & 1 & 2 & 3 & 4 & 5 & 6 \\
\hline 1 & Satisfaction & 3.801 & 0.603 & 1.000 & & & & & \\
\hline 2 & Integrative Care & 3.979 & 0.730 & $0.283^{\star \star}$ & 1.000 & & & & \\
\hline 3 & Reputation & 3.647 & 0.857 & 0.358 ** & $0.732^{\star \star *}$ & 1.000 & & & \\
\hline 4 & Payment & 3.805 & 0.737 & $0.194^{\star *}$ & $0.075^{\star \star}$ & $0.080 * *$ & 1.000 & & \\
\hline 5 & Inter_1 & 15.180 & 4.222 & $0.334^{\star \star}$ & $0.707 * \star$ & $0.536^{\star *}$ & $0.746^{\star *}$ & 1.000 & \\
\hline 6 & Inter_2 & 13.925 & 4.440 & $0.393^{\star \star}$ & $0.582^{\star \star}$ & $0.784^{\star \star}$ & $0.666^{\star \star}$ & 0.860 ** & 1.000 \\
\hline \multicolumn{10}{|c|}{ ** $\rho<0.01$} \\
\hline \multicolumn{10}{|c|}{ Inter_1 = Interaction (Integrative Care_X_Payment) } \\
\hline
\end{tabular}

Table 5

Model summary for the regression analysis

Model Summary

Outcome: Patient satisfaction

\begin{tabular}{|c|c|c|c|c|c|c|c|c|c|c|}
\hline \multirow[t]{2}{*}{ Predictors } & \multirow[t]{2}{*}{ Model } & \multirow[t]{2}{*}{$\mathbf{R}$} & \multirow{2}{*}{$\begin{array}{l}\mathrm{R} \\
\text { Square }\end{array}$} & \multirow{2}{*}{$\begin{array}{l}\text { Adjusted } \\
\text { R Square }\end{array}$} & \multirow{2}{*}{$\begin{array}{l}\text { Std. Error of } \\
\text { the Estimate }\end{array}$} & \multicolumn{5}{|c|}{ Change Statistics } \\
\hline & & & & & & $\begin{array}{l}\text { R Square } \\
\text { Change }\end{array}$ & $\begin{array}{l}\mathbf{F} \\
\text { Change }\end{array}$ & df1 & df2 & $\begin{array}{l}\text { Sig. } F \\
\text { Change }\end{array}$ \\
\hline \multirow{2}{*}{$\begin{array}{l}\text { (A) Reputation, } \\
\text { Integrative care }\end{array}$} & 1 & $.360^{\mathrm{a}}$ & .129 & .128 & .563 & .129 & 106.866 & 2 & 1438 & .000 \\
\hline & 2 & $.360^{\mathrm{b}}$ & .129 & .128 & .564 & .000 & .076 & 1 & 1437 & .783 \\
\hline \multirow{2}{*}{$\begin{array}{l}\text { (B) Payment, } \\
\text { Integrative care }\end{array}$} & 1 & $.332^{\mathrm{c}}$ & .110 & .109 & .570 & .110 & 88.913 & 2 & 1438 & .000 \\
\hline & 2 & $.349^{d}$ & .121 & .120 & .566 & .011 & 18.652 & 1 & 1437 & .000 \\
\hline \multicolumn{11}{|c|}{ a. Predictors: (Constant), reputation, Integrative Care } \\
\hline \multicolumn{11}{|c|}{ b. Predictors: (Constant), Reputation, Integrative Care, IntegrativeCare_x_Reputation } \\
\hline \multicolumn{11}{|c|}{ c. Predictors: (Constant), Payment, Integrative Care } \\
\hline
\end{tabular}


Table 6

The mediation effect of reputation on the relationship between integrative care and satisfaction. Outcome of PROCESS model code 4

\begin{tabular}{|lllllllll|}
\hline Outcome & Effect Type & $\boldsymbol{\beta}$ & $\mathbf{S E}$ & $\mathbf{t}$ & $\mathrm{R}-\mathrm{sq}$ & $\boldsymbol{\rho}$ & LLCl & ULCl \\
\hline Satisfaction & Model Summary & & & & 0.1294 & 0.0000 & & \\
\cline { 2 - 9 } & Total Direct Effect & 0.2342 & 0.0209 & 11.2013 & & 0.0000 & 0.1932 & 0.2753 \\
& Direct Effect & 0.371 & 0.0299 & 1.2430 & & 0.2141 & -0.0215 & 0.0957 \\
& Indirect Effect & 0.1971 & 0.0225 & & & & 0.1531 & 0.2415 \\
\hline
\end{tabular}

In order to prove hypotheses 3, we first used regression menu of SPSS to determine any potential moderation. Table 5(B) represents the results of using regression tests. The table shows that the changes in F values for two models, (1) without interaction, and (2) with interactions are significant. The results of Table $5(B)$ indicate indicates that $R^{2}$ change in model 1 is significant $(F(2,1438)=$ $88.913, \rho<0.001)$ as well as in model $2(F(1,1437)=18,652, \rho<0.001)$. In addition, Table 4 shows that satisfaction correlates positively $(\rho<0.01)$ with both integrative care and costs. These results indicate that costs will have potentially moderation role affecting the relationship between integrative care and satisfaction.

The first part of Table 7 represents the outcome of using PROCESS model 1, in which costs proposed to moderate the relationship between integrative care and satisfaction. The results show the interaction between integrative care and costs is significant $(\rho<$ $0.001)$ with confidence range does not include zero $(0.0642,0.1710)$. This outcome indicates that hypothesis 3 is satisfied. Figure 1(B) depicts the diagram representing the PROCESS model 1, and Fig. 3(A) shows graphically the effect of costs on the direction of integrative care - satisfaction relationship. 
Table 7

The moderation effect of payment. Outcome of PROCESS tool using model codes 1, 59 and 7

\begin{tabular}{|c|c|c|c|c|c|c|c|c|c|}
\hline $\begin{array}{l}\text { Model } \\
\text { Code }\end{array}$ & Outcome & Variable / Summary & $\beta$ & SE & $\mathrm{t}$ & R-sq & $\rho$ & LLCl & ULCI \\
\hline \multirow[t]{4}{*}{1} & \multirow[t]{4}{*}{ Satisfaction } & Model Summary & & & & 0.1215 & 0.0000 & & \\
\hline & & Interactive care & 0.2254 & 0.0205 & 10.9866 & & 0.0000 & 0.1852 & 0.2656 \\
\hline & & Payment & 0.1401 & 0.0203 & 6.8961 & & 0.0000 & 0.1002 & 0.1799 \\
\hline & & $\begin{array}{l}\text { Int-1 } \\
\text { (InteractiveCare_x_Payment) }\end{array}$ & 0.1176 & 0.0272 & 4.3189 & & 0.0000 & 0.0642 & 0.1710 \\
\hline \multirow[t]{10}{*}{59} & \multirow[t]{4}{*}{ Reputation } & Model Summary & & & & 0.5363 & 0.000 & & \\
\hline & & Interactive care & 0.8580 & 0.0212 & 40.5343 & & 0.000 & 0.8165 & 0.8995 \\
\hline & & Payment & 0.0266 & 0.0210 & 1.4122 & & 0.581 & $\overline{0} .0115$ & 0.0707 \\
\hline & & $\begin{array}{l}\text { Int-1 } \\
\text { (InteractiveCare_x_Payment) }\end{array}$ & 0.0107 & 0.0281 & 0.3793 & & 0.0 .7045 & $\overline{0} .0445$ & 0.0658 \\
\hline & \multirow[t]{6}{*}{ Satisfaction } & Model Summary & & & & 0.1677 & 0.0000 & & \\
\hline & & Interactive Care & 0.0351 & 0.0293 & 1.2001 & & 0.2303 & $\overline{0} .0223$ & 0.0925 \\
\hline & & Reputation & 0.2216 & 0.0249 & 8.8983 & & 0.0000 & 0.1727 & 0.2704 \\
\hline & & Payment & 0.1336 & 0.0193 & 6.7463 & & 0.0000 & 0.0947 & 0.1724 \\
\hline & & $\begin{array}{l}\text { Int-1 } \\
\text { (InteractiveCare_x_Payment) }\end{array}$ & 0.0964 & 0.0402 & 2.3999 & & 0.0165 & 0.0176 & 0.1751 \\
\hline & & $\begin{array}{l}\text { Int-2 } \\
\text { (Reputation_x_Payment) }\end{array}$ & 0.0220 & 0.0352 & 0.6263 & & 0.5312 & $\overline{0} .0470$ & 0.0910 \\
\hline \multirow[t]{11}{*}{14} & \multirow[t]{2}{*}{ Reputation } & Model Summary & & & & 0.5358 & 0.0000 & & \\
\hline & & Interactive Care & 0.8601 & 0.0211 & 40.7549 & & 0.0000 & 0.8187 & 0.9015 \\
\hline & \multirow[t]{9}{*}{ Satisfaction } & Model Summary & & & & 0.1643 & 0.0000 & & \\
\hline & & Interactive Care & 0.0340 & 0.0293 & 1.1600 & & 0.2462 & $\overline{0} .0335$ & 0.0915 \\
\hline & & Reputation & 0.2216 & 0.0249 & 8.8849 & & 0.0000 & 0.1727 & 0.2706 \\
\hline & & Payment & 0.1344 & 0.0198 & 6.7765 & & 0.0000 & 0.0955 & 0.1733 \\
\hline & & $\begin{array}{l}\text { Int-1 } \\
\text { (Reputation_x_Payment) }\end{array}$ & 0.0854 & 0.0233 & 3.6694 & & 0.0003 & 0.0397 & 0.1310 \\
\hline & & $\begin{array}{l}\text { Direct effect of Interactive } \\
\text { Care on satisfaction }\end{array}$ & 0.0340 & 0.0293 & 1.1600 & & 0.2462 & $\overline{0} .0235$ & 0.0915 \\
\hline & & $\begin{array}{l}\text { Indirect effect with Payment } \\
\text { index }=-0.8047\end{array}$ & 0.1315 & 0.0294 & & & & 0.0733 & 0.1891 \\
\hline & & $\begin{array}{l}\text { Indirect effect with Payment } \\
\text { index }=-0.0047\end{array}$ & 0.1903 & 0.0221 & & & & 0.1474 & 0.2340 \\
\hline & & $\begin{array}{l}\text { Indirect effect with Payment } \\
\text { index }=0.7953\end{array}$ & 0.2490 & 0.0270 & & & & 0.1972 & 0.3031 \\
\hline
\end{tabular}

\section{Testing roles of reputation and costs together}

PROCESS tool Model 59 is suitable for testing the conceptual model as presented in Fig. 1C. The second part of Table 7 depicts the related data extracted from the outcome of the PROCESS tool (model code 59). The results show that where the reputation is an 
outcome, the interaction (Integrative Care * Costs) is insignificant $(\rho=0.7045)$ and the confidence band include zero $(-0.0445$, 0.0658). However, where satisfaction is outcome, the interaction (Integrative Care * Costs) becomes significant $(\rho=0.0165)$ with confidence bands $(0.0176,0.1751)$ does not include zeros, while the interaction (Reputation * Costs) is insignificant $(\rho=0.5312)$ and confidence range $(-0.0470,0.0910)$ includes zero. These results indicate that in presence of reputation, costs variable moderates only one relationship that is the relationship between reputation and satisfaction. To further verify this results we run PROCESS toll model 7 and model 14. The results confirm the finding that costs construct moderates the relationship between reputation and satisfaction (Fig. 1(D)). Accordingly, hypothesis 5 is satisfied while hypotheses 4 and 6 are not satisfied. Figure 3(B) depicts graphically the effect of costs on the direction of reputation - satisfaction relationship.

In summary, our data analysis shows that hypotheses $1(\mathrm{a}-\mathrm{c}), 2,3$, and 5 are supported., while hypotheses 4 and 6 are not supported.

\section{Discussion}

There are two main dimensions for service quality: technical quality dimension and functional quality dimension. Due to lack of skill and knowledge to properly evaluate the technical quality, the patients' evaluation of hospital service quality is influenced by functional quality, and mainly, by the interactive care. In this study, the integrative care comprises eight indicators. Five of these indicators are associated with doctor-patient interaction. The other three indicators are associated with the environment during doctor's diagnosis. There are three reasons for our selection of indicators for interactive care. First, patients expect from doctors to diagnose illness and provide correct treatment and, accordingly, interaction of doctor with a patient is an essential element for patient's expectation. Second, our questionnaire was distributed among outpatients where the interaction mainly with the doctors, and third, privacy, interference of other staff, answering telephone call during diagnosis are issues significantly affect the perceived technical and functional dimensions of service by patients.

There is strong direct correlation between satisfaction and intentional behaviour of a patient. Satisfied patients are more likely recommend the hospital to other patients and friends and to be royal to the hospital. Accordingly, the satisfaction variable, in our research, comprises both traditional satisfaction elements (three variables) and intentional behavioural elements (four variables).

Much research works considers corporate image of an organisation and its effect on satisfaction. Corporate image is a very complex variable includes large number of indicators and widely used in marketing literature. Our research considers one important part of corporate image, that is, hospital's reputation. Patients on their selection of a hospital care mainly about the medical treatment of the hospitals. Accordingly, indicators related to reputation of the hospital on diagnosis and treatment, rather than marketing elements, plays the major role on hospital's selection. In this regard, patients most likely take into consideration the reputation of the hospitals as stated in different widely available sources including social media and mainly WECHAT. It is important to note that WeChat is the most frequently used social media in China and is widely used to obtain individual opinions on healthcare services [79; 80; 81]. Other sources for obtaining information regarding hospital reputation include friends, family, and other patients. Regarding costs (payment) variable, we considered factors associated with the details of payment bill, its adequacy to the treatment, transparency and clarity, and the explanation of the hospital staff.

Our results give indication that patients look to hospital reputation as more important factor reflecting the hospital integrative care and hence its treatment quality than the costs. In addition, high and costs or poor payment administration may affect the patient satisfaction, but its effect is much less on the hospital's reputation. Our research shows that patients depend highly on data available in social media in their perception on hospital reputation. Beside social media, other items affecting the hospital's reputation are perceived reputation of the hospital professionals, ranking of hospital by government and the participation of the hospital in social activities. However, the analysis shows that item related to the hospital published materials and advertisement do not improve the hospital reputation in comparison to other four items.

With respect to integrative care, six items out of eight items were considered. The patients valued the privacy during diagnosis beside five items. One item related to convenience of the patient to discuss illness and treatment with doctor. The other four items are related to the way doctor treat the patient; doctor's ability to listen, treating patient as individual, explanation, and willingness to answer patient's questions. The two items which did not considered as a result of factor analysis are interferences of nurses and other staff during the diagnosis and answering telephone calls during diagnosis. The study finds that there was very high factor covariances between privacy and interferences. That is, maintaining privacy during diagnosis implies preventing or reducing interferences from 
other staff and avoiding answering telephone call during diagnosis. The respondents did not consider answering telephone call by doctors as an issue affecting interactive care as far as the other items maintained during the diagnosis.

Many research works refer to the costs as major factor influencing the patient's satisfaction [23; 24;62]. However, our research indicates that the effect of costs on satisfaction should not be separated from the effect of reputation. Where the relationship between integrative care and satisfaction is considered in insolation from reputation, the costs variable moderates the relationship. In presence of reputation. costs variable will affect only on the reputation-Satisfaction relationship and its direct effect on satisfaction would be limited. This outcome validates the conclusions of other research works, (see for example [24]), that hospital reputation is more important factor than costs or costs in the selection of the hospital. Our outcome gives also a reason as why many patients from rural area manage appointment with doctors in hospitals in urban area rather than having appointment with doctor in the Rural Community hospitals, which have lower reputation. During discussion with patients from rural area, many patients expressed that they are not happy with the high costs of the selected hospitals rather than with the long way they suffer to arrive the selected hospitals, but they accept costs because of their perception that the selected hospital provide better diagnosis and treatment. It is not surprising that there is considerable increase in the patient legal complaints against hospitals because the outcome of the treatment as perceived by patients don't match the required costs [82].

In addition, our analysis validates the outcome of some studies indicating that the healthcare providers with higher expenses provide better care are not true always. DiCenzo and Freedman [57], for example, stress that the highest paid providers do not necessarily provide the highest quality of care.

\section{Conclusion}

This research empirically tested the roles of hospital reputation and its cost system on the relationship between hospital's interactive care and patient satisfaction. A self-administrated questionnaire was distributed randomly among outpatients in five large hospitals located at Zhejiang Province, China. Controlled common method bias test was conducted to ensure that the common variance is not a major concern in data analysis. One-factor congeneric measurement was employed to test fitness of factors assigned to variables. Data were further tested for convergence validity, and internal and item reliability. SPSS v. 25 software with PROCESS v.3.3 model in a bootstrap approach were used to test the mediation and moderation effects. A total 1441 valid responses were received and 22 questionnaire items out of 25 items survived the factor analysis and common method bias tests. Results show significant positive correlation $(\rho<0.01)$ between the model's variables, with correlation between interactive care and reputation $(0.732)$ is the highest. The analysis indicates the hospital reputation moderates the relationship between hospital's reputation and patient satisfaction. It also illustrates that poor payment administration may affect the patient satisfaction, but its effect is much less on the hospital's reputation. Results indicate that the hospital reputation moderates the relationship between hospital's reputation and patient satisfaction. It also illustrates that poor payment administration may affect the patient satisfaction, but its effect is much less on the hospital's reputation. Our research shows that patients depend highly on data available in social media in their perception on hospital reputation. This research validates two assertions of other research works. First, hospital reputation is more important factor than costs in the selection of the hospital, and second, the perception that healthcare providers with higher expenses provide better care are not true always. Further, our research gives a reason as why many patients from rural area usually manage appointments with doctors in hospitals in urban area rather than having appointment with doctor in the Rural Community hospitals, which have lower reputation.

\section{Abbreviations}

SRW :Standard Regression Weight

RMSEA: Root Mean Square Error of Approximation

RMR: Root Mean Square

GFI : Goodness-of-Fit

SMC: Squared multiple correlation 


\section{Declarations}

Ethics approval and consent to participate: All survey procedures were performed in accordance with the ethic guidelines and approved by the Ethics Committee of Zhejiang University City College and Quality and Ethics Management Institute of Enze Hospital, China. The opining letter attached to the questionnaire highlighted that answering the questionnaire is voluntary and constitutes consent of the respondent.

Consent for publication: Not applicable.

Availability of data and materials: We attached the Excel file of the data.

Competing interests: WL and LH have no financial and competing interest from the publication of this paper.

Funding: This paper is supported by the Enze Hospital Management Institute and Research Base of Philosophy and Social Science in Hangzhou-Center for Research of CSR and Sustainable Development, China. Enze Hospital Management Institute assisted the design of data collection. ZUCC supported literature database.

Author contribution: WL obtained the funding, administrated the survey and data collection. LH constructed research methodology. All authors contributed to the formulation of the questionnaire, data analysis and writing the manuscript. All authors have read and approved the manuscript.

Acknowledgements :Acknowledgement will be supplied later.

\section{References}

1. Gill L, White L. A critical review of patient satisfaction. Leadership in Health Services. 2009;22:8-19.

2. Gupta D, Rodeghier M, Lis CG. Patient satisfaction with service quality in an oncology setting: implications for prognosis in nonsmall cell lung cancer. International journal for quality in health care. 2013;25:696-703.

3. Nelson EC, Rust RT, Zahorik A, Rose RL, Batalden P, Siemanski BA. Do patient perceptions of quality relate to hospital financial performance? Journal of Health Care Marketing 12 (1992).

4. Kalman TP. An overview of patient satisfaction with psychiatric treatment. Psychiatric Services. 1983;34:48-54.

5. Eberting JJ, Straja SR, Tuncay OC. Treatment time, outcome, and patient satisfaction comparisons of Damon and conventional brackets. Clinical Orthodontics Research. 2001;4:228-34.

6. Vincent N, Lionberg C. Treatment preference and patient satisfaction in chronic insomnia. Sleep. 2001;24:411-7.

7. Hirsh AT, Atchison JW, Berger JJ, Waxenberg LB, Lafayette-Lucey A, Bulcourf BB, Robinson ME. Patient satisfaction with treatment for chronic pain: predictors and relationship to compliance. Clin J Pain. 2005;21:302-10.

8. Gupta D, Rodeghier M, Lis CG. Patient satisfaction with service quality as a predictor of survival outcomes in breast cancer. Support Care Cancer. 2014;22:129-34.

9. Kim J-W. A Study of the Relationship between the Outbound Call Center Service Quality and Service Recovery Customer Royalty. Journal of Digital Convergence. 2015;13:163-76.

10. Kessler DP, Mylod D. Does patient satisfaction affect patient loyalty? International journal of health care quality assurance. 2011;24:266-73.

11. Finkelstein BS, Harper DL, Rosenthal GE. Patient assessments of hospital maternity care: a useful tool for consumers? Health services research. 1999;34:623.

12. Amin M, Zahora Nasharuddin S. Hospital service quality and its effects on patient satisfaction and behavioural intention. Clin Gov Int J. 2013;18:238-54.

13. Ahmed F, Burt J, Roland M. Measuring patient experience: concepts and methods. The Patient-Patient-Centered Outcomes Research. 2014;7:235-41.

14. Jalil A, Zakar R, Zakar MZ, Fischer F. Patient satisfaction with doctor-patient interactions: a mixed methods study among diabetes mellitus patients in Pakistan. BMC Health Serv Res. 2017;17:155. 
15. Östlund U, Wennman-Larsen A, Gustavsson P, Wengström Y. What symptom and functional dimensions can be predictors for global ratings of overall quality of life in lung cancer patients? Support Care Cancer. 2007;15:1199-205.

16. Ware JE Jr, Snyder MK, Wright WR, Davies AR. Defining and measuring patient satisfaction with medical care. Eval Program Plan. 1983;6:247-63.

17. Mira JJ, Lorenzo S, Navarro I. Hospital reputation and perceptions of patient safety. Medical Principles Practice. 2014;23:92-4.

18. Dijs-Elsinga J, Otten W, Versluijs MM, Smeets HJ, Kievit J, Vree R, van der Made WJ. and P.J. Marang-van de Mheen, Choosing a hospital for surgery: the importance of information on quality of care. Med Decis Making. 2010;30:544-55.

19. Sehgal AR. The role of reputation in US News \& World Report's rankings of the top 50 American hospitals. Ann Intern Med. 2010;152:521-5.

20. Pilny A, Mennicken R. Does hospital reputation influence the choice of hospital? Ruhr Economic Paper (2014).

21. Jung K, Feldman R, Scanlon D. Where would you go for your next hospitalization? J Health Econ. 2011;30:832-41.

22. Abd-El-Salam EM, Shawky AY, El-Nahas T. The impact of corporate image and reputation on service quality, customer satisfaction and customer loyalty: testing the mediating role. Case analysis in an international service company. The Business Management Review. 2013;3:177.

23. Blizzard R, Hospital Bills May Cost Patient Satisfaction, Gallup Healthcare, 2004.

24. Jacobsen KH, Ansumana R, Abdirahman HA, Bockarie AS, Bangura U, Meehan KA, Jimmy DH, Malanoski AP, Sundufu AJ, Stenger DA. Considerations in the selection of healthcare providers for mothers and children in Bo, Sierra Leone: reputation, cost and location. International Health. 2012;4:307-13.

25. Siddiqui N, Khandaker SA. Comparison of services of public, private and foreign hospitals from the perspective of Bangladeshi patients. J Health Popul Nutr. 2007;25:221.

26. Jacobs EA, Sadowski LS, Rathouz PJ. The impact of an enhanced interpreter service intervention on hospital costs and patient satisfaction. J Gen Intern Med. 2007;22:306-11.

27. Hayes AF, Introduction to mediation, moderation, and conditional process analysis: A regression-based approach, Guilford Publications, 2017.

28. Kitapci O, Akdogan C, Dortyol IT. The impact of service quality dimensions on patient satisfaction, repurchase intentions and word-of-mouth communication in the public healthcare industry. Procedia-Social Behavioral Sciences. 2014;148:161-9.

29. Grönroos C. A service quality model and its marketing implications. European Journal of marketing. 1984;18:36-44.

30. Swan JE, Combs LJ. Product Performance and Consumer Satisfaction: A New Concept: An Empirical Study Examines the Influence of Physical and Psychological Dimensions of Product Performance on Consumer Satisfaction. Journal of marketing. 1976;40:25-33.

31. Parasuraman A, ZeithamI VA, Berry LL. A conceptual model of service quality and its implications for future research. Journal of marketing. 1985;49:41-50.

32. Parasuraman A, ZeithamI VA, Berry LL. Servqual: A multiple-item scale for measuring consumer perc. Journal of retailing. 1988;64:12.

33. Mangold G, Babakus E. Service quality: The front-stage vs. the back-stage perspective. J Serv Mark. 1991;5:59-70.

34. Glushko RJ, Tabas L, Bridging the "front stage" and "back stage" in service system design, Proceedings of the 41st Annual Hawaii International Conference on System Sciences (HICSS 2008), IEEE, 2008, pp. 106-106.

35. Parasuraman A, ZeithamI VA, Berry LL. Communication and control processes in the delivery of service quality. Journal of marketing. 1988;52:35-48.

36. Coutinho ED, da Costa Vieira PR, de Queirós CL, Mattoso IR, Troccoli, Renni MJP. Influence of service quality and corporate image on the satisfaction of patients with Brazil's National Cancer Institute. International Journal of Pharmaceutical Healthcare Marketing. 2019;13:447-68.

37. Schembri S. Experiencing health care service quality: through patients' eyes. Aust Health Rev. 2015;39:109-16.

38. Taub SJ. The Internet's role in patient/physician interaction: bringing our understanding in line with online reality. Compr Ophthalmol Update. 2006;7:25-30.

39. Ong LM, De Haes JC, Hoos AM, Lammes FB. Doctor-patient communication: a review of the literature. Soc Sci Med. 1995;40:903-18.

Page 17/25 
40. Ruusuvuori J. Looking means listening: coordinating displays of engagement in doctor-patient interaction. Soc Sci Med. 2001;52:1093-108.

41. Dhaliwal SK, Hunt RH. Doctor-patient interaction for irritable bowel syndrome in primary care: a systematic perspective. Eur J Gastroenterol Hepatol. 2004;16:1161-6.

42. Dagger TS, Sweeney JC, Johnson LW. A hierarchical model of health service quality: scale development and investigation of an integrated model. Journal of service research. 2007;10:123-42.

43. Drenkard K, Swartwout E, Deyo P, O'Neil MB Jr. Interactive care model: a framework for more fully engaging people in their healthcare. JONA: The Journal of Nursing Administration. 2015;45:503-10.

44. Wong AM, Chang W-H, Ke P-C, Huang C-K, Tsai T-H, Chang H-T, Shieh W-Y, Chan H-L, Chen C-K, Pei Y-C. Technology acceptance for an Intelligent Comprehensive Interactive Care (ICIC) system for care of the elderly: a survey-questionnaire study. PloS one. 2012;7:e40591.

45. Krouse HJ, Roberts SJ. Nurse-Patient Interactive Styles Power, Control, and Satisfaction. West J Nurs Res. 1989;11:717-25.

46. McDougall GH, Levesque TJ. A revised view of service quality dimensions: an empirical investigation. Journal of professional services marketing. 1995;11:189-210.

47. Gotlieb JB, Grewal D, Brown SW. Consumer satisfaction and perceived quality: complementary or divergent constructs? Journal of applied psychology. 1994;79:875-85.

48. Mosadeghrad AM. Factors influencing healthcare service quality. International journal of health policy management. 2014;3:7789.

49. Curry A, Sinclair E. Assessing the quality of physiotherapy services using SERVQUAL. International Journal of Health Care Quality Assurance. 2002;15:197-205.

50. Ladhari R. Service quality, emotional satisfaction, and behavioural intentions: A study in the hotel industry. Managing Service Quality: An International Journal. 2009;19:308-31.

51. Oliver RL, Rust R. Service quality: Insights and managerial implication from the frontier. Journal of Service Quality. 1994;15:3243.

52. Cronin JJ Jr, Brady MK, Hult GTM. Assessing the effects of quality, value, and customer satisfaction on consumer behavioral intentions in service environments. Journal of retailing. 2000;76:193-218.

53. Wu C-C. The impact of hospital brand image on service quality, patient satisfaction and loyalty. Afr J Bus Manage. 2011;5:487382.

54. ZeithamI VA, Berry LL, Parasuraman A. The behavioral consequences of service quality. Journal of marketing. 1996;60:31-46.

55. Petaschinck J. ospital billing processes affect patients' satisfaction. The Recivable Report. 2012;27:10-1.

56. Yanagisawa S, Mey V, Wakai S. Comparison of health-seeking behaviour between poor and better-off people after health sector reform in Cambodia. Public Health. 2004;118:21-30.

57. DiCenzo D, Freedman J. Re-examining the Health Care Cost Drivers and Trends in the Commonwealth: A Review of State Reports (2008-2018), Freedman Healthcare, 2019, pp. 24.

58. Baji P, Pavlova M, Gulácsi L, Groot W. User fees for public health care services in Hungary: Expectations, experience, and acceptability from the perspectives of different stakeholders. Health Policy. 2011;102:255-62.

59. Suchman AL, Roter D, Green M, Lipkin M Jr. T.C.S.G.o.t.A.A.o. Physician, and Patient, Physician satisfaction with primary care office visits. Medical care (1993) 1083-1092.

60. Novack DH, Suchman AL, Clark W, Epstein RM, Najberg E, Kaplan C. Calibrating the physician: personal awareness and effective patient care. Jama. 1997;278:502-9.

61. Kenagy JW, Berwick DM, Shore MF. Service quality in health care. Jama. 1999;281:661-5.

62. White C, Reschovsky JD, Bond AM. Understanding differences between high-and low-price hospitals: implications for efforts to rein in costs. Health Aff. 2014;33:324-31.

63. Antons D, Salge TO, Barrett M, Kohli R, Oborn E, The Social Value of Information Technology: How IT Investments Enhance Hospital Reputation, Academy of Management Proceedings, Academy of Management Briarcliff Manor, NY 10510, 2015, pp. 16671. 
64. Yang A, Chimonas S, Bach PB, Taylor DJ, Lipitz-Snyderman A. Critical choices: what information do patients want when selecting a hospital for cancer surgery? Journal of oncology practice. 2018;14:e505-12.

65. Dabholkar PA, Shepherd CD, Thorpe DI. A comprehensive framework for service quality: an investigation of critical conceptual and measurement issues through a longitudinal study. Journal of retailing. 2000;76:139-73.

66. Dragovic M, Towards an improved measure of the Edinburgh Handedness Inventory: A one-factor congeneric measurement model using confirmatory factor analysis. Laterality: Asymmetries of Body, Brain and Cognition 9 (2004) 411-419.

67. Fisher MJ, King J. The self-directed learning readiness scale for nursing education revisited: A confirmatory factor analysis. Nurse Educ Today. 2010;30:44-8.

68. Joreskog KG, Statistical analysis of sets of congeneric tests. ETS Research Report Series 1969 (1969).

69. Hair J Jr, Black W, Babin B, Anderson R, Tatham R. SEM: An introduction. Multivariate data analysis: A global perspective (2010) 629-686.

70. Heck RH, Thomas SL, An introduction to multilevel modeling techniques: MLM and SEM approaches using Mplus, Routledge, 2015.

71. Podsakoff PM, MacKenzie SB, Lee J-Y, Podsakoff NP. Common method biases in behavioral research: a critical review of the literature and recommended remedies. Journal of applied psychology. 2003;88:879.

72. Williams LJ, Hartman N, Cavazotte F. Method variance and marker variables: A review and comprehensive CFA marker technique. Organizational research methods. 2010;13:477-514.

73. Podsakoff PM, MacKenzie SB, Podsakoff NP. Sources of method bias in social science research and recommendations on how to control it. Ann Rev Psychol. 2012;63:539-69.

74. Mardia KV. Applications of some measures of multivariate skewness and kurtosis in testing normality and robustness studies. Sankhyā: The Indian Journal of Statistics, Series B (1974) 115-128.

75. Jondeau E, Rockinger M. Conditional volatility, skewness, and kurtosis: existence, persistence, and comovements. Journal of Economic dynamics Control. 2003;27:1699-737.

76. Kim H-Y. Statistical notes for clinical researchers: assessing normal distribution (2) using skewness and kurtosis. Restorative dentistry endodontics. 2013;38:52-4.

77. Holmes-Smith P, Advanced structural equation modelling using AMOS, Workshop material provided at the ACSPRI, 2011.

78. Hayes AF. Introduction to Mediation, Moderation, and Conditional Process Analysis: A Regression-Based Approach. New York: The Guilford Press; 2013.

79. Zhang X, Wen D, Liang J, Lei J. How the public uses social media wechat to obtain health information in china: a survey study. BMC Med Inf Decis Mak. 2017;17:71-9.

80. Xu Z-j, Liu X-r, Cadet B. The investigation of current situation of application on WeChat public platform by community health services centers in Shanghai. Chinese Journal of General Practice (2017) 29.

81. Peng P, Jindong L, Chen L, Yang X. Construction of Hospital Service System Based on WeChat Public Platform. Journal of Medical Informatics (2015) 39-41.

82. Jiang Y, Ying X, Zhang Q, Tang SR, Kane S, Mukhopadhyay M, Qian X. Managing patient complaints in China: a qualitative study in Shanghai. BMJ open. 2014;4:e005131.

\section{Figures}




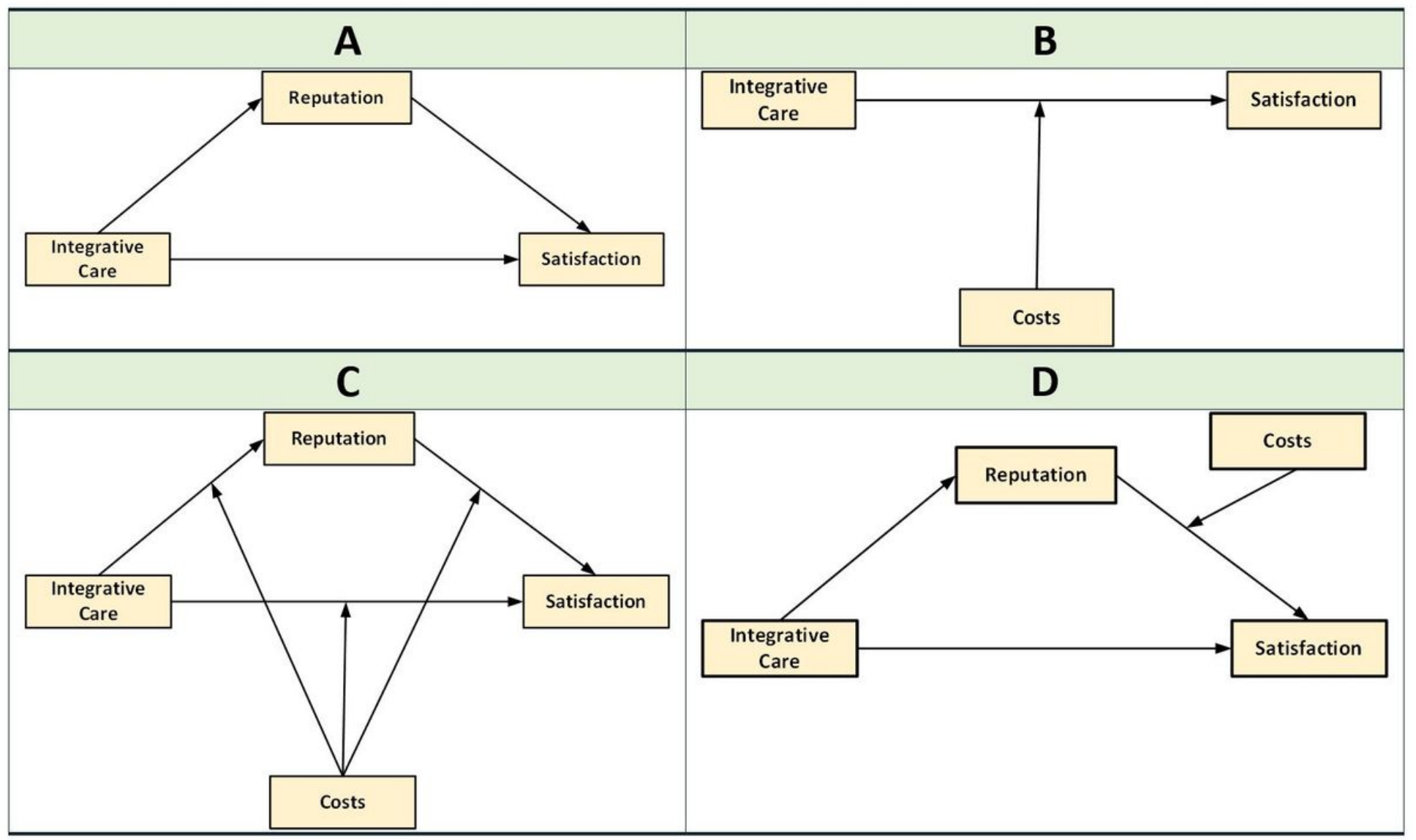

\section{Figure 1}

Graphical representation of various relationships between research variables for PROCESS tool; A. PROCESS model code 4, B. PROCESS model code 1, C. PROCESS model code 59, D. PROCESS model code 7. 


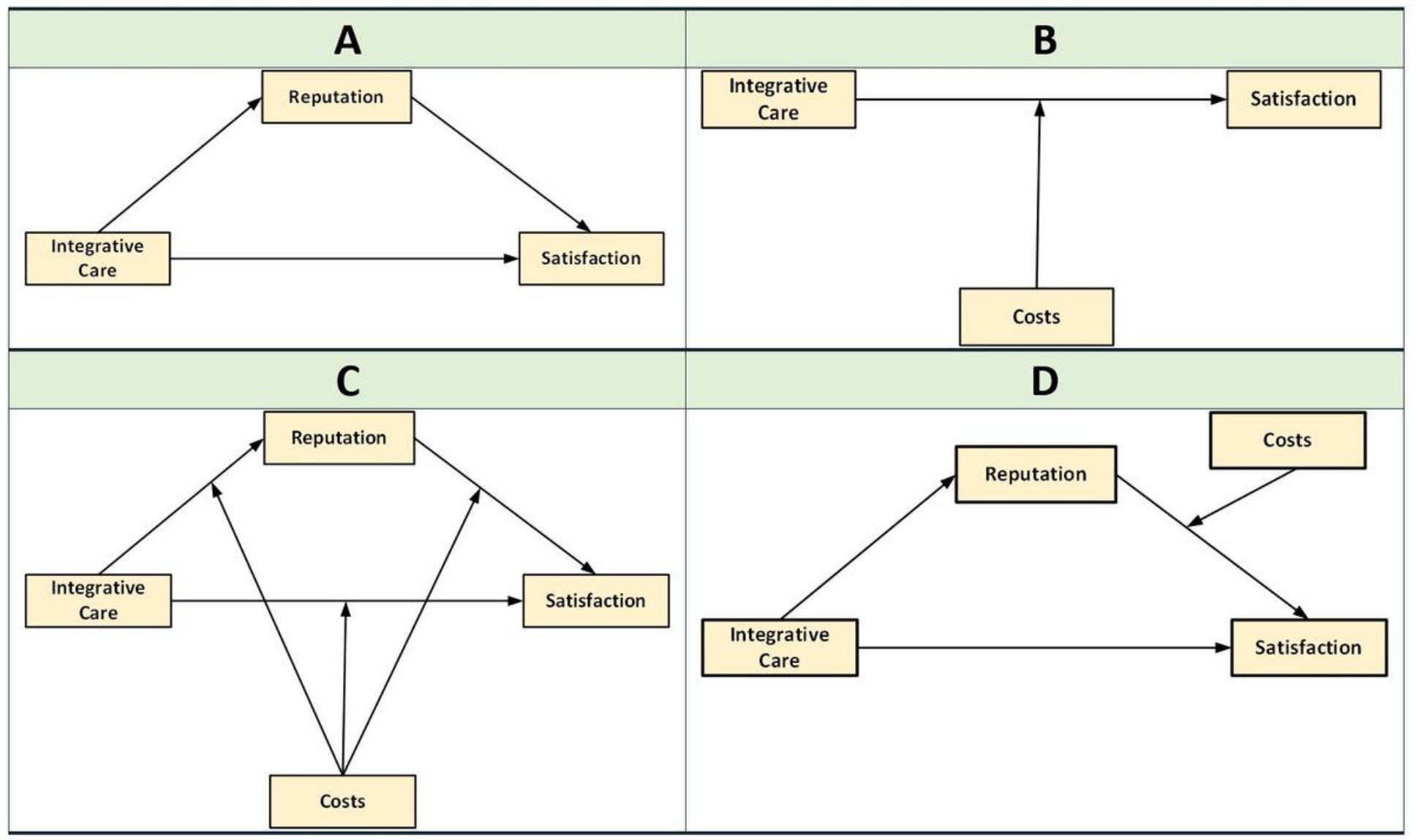

\section{Figure 1}

Graphical representation of various relationships between research variables for PROCESS tool; A. PROCESS model code 4, B. PROCESS model code 1, C. PROCESS model code 59, D. PROCESS model code 7. 


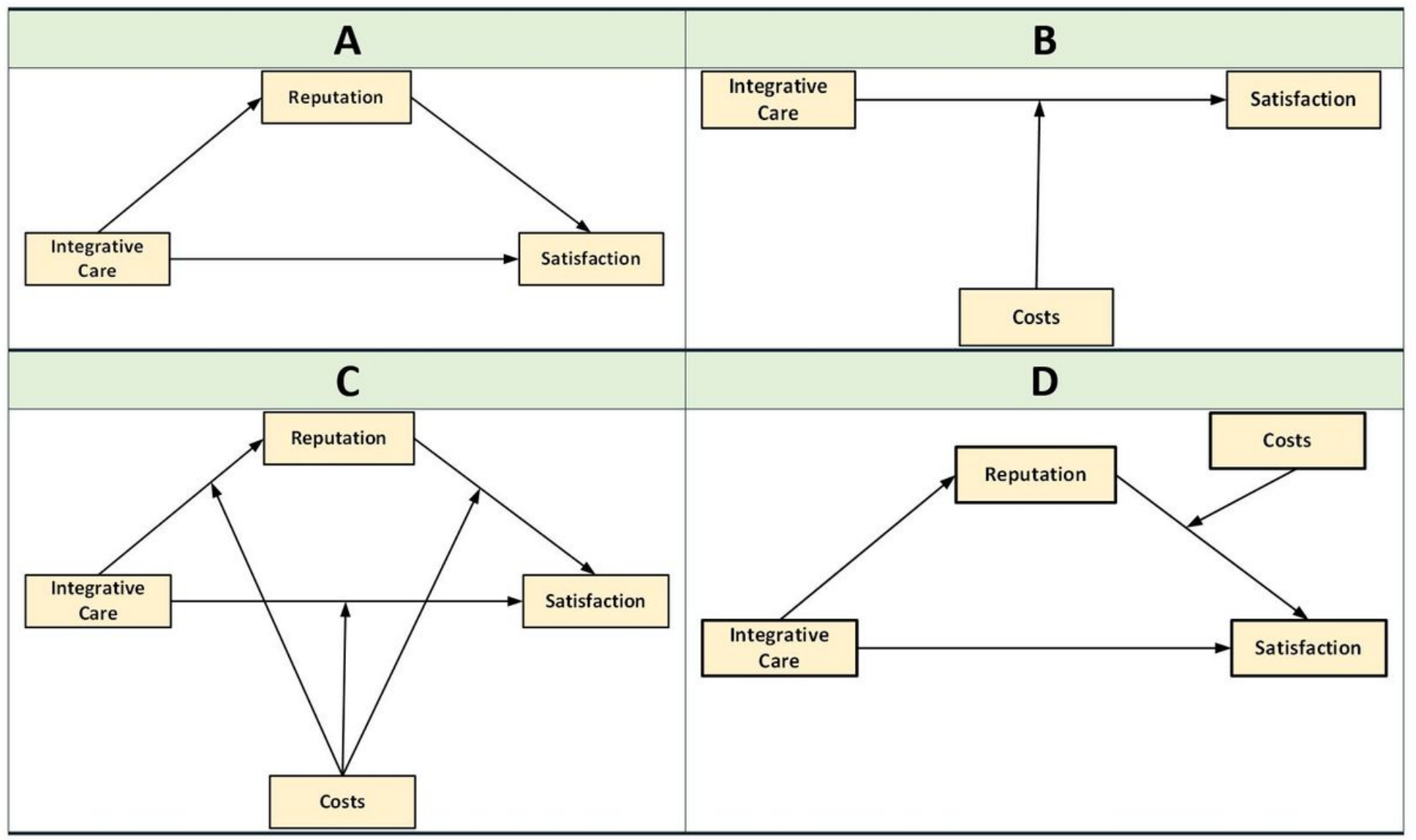

\section{Figure 1}

Graphical representation of various relationships between research variables for PROCESS tool; A. PROCESS model code 4, B. PROCESS model code 1, C. PROCESS model code 59, D. PROCESS model code 7. 


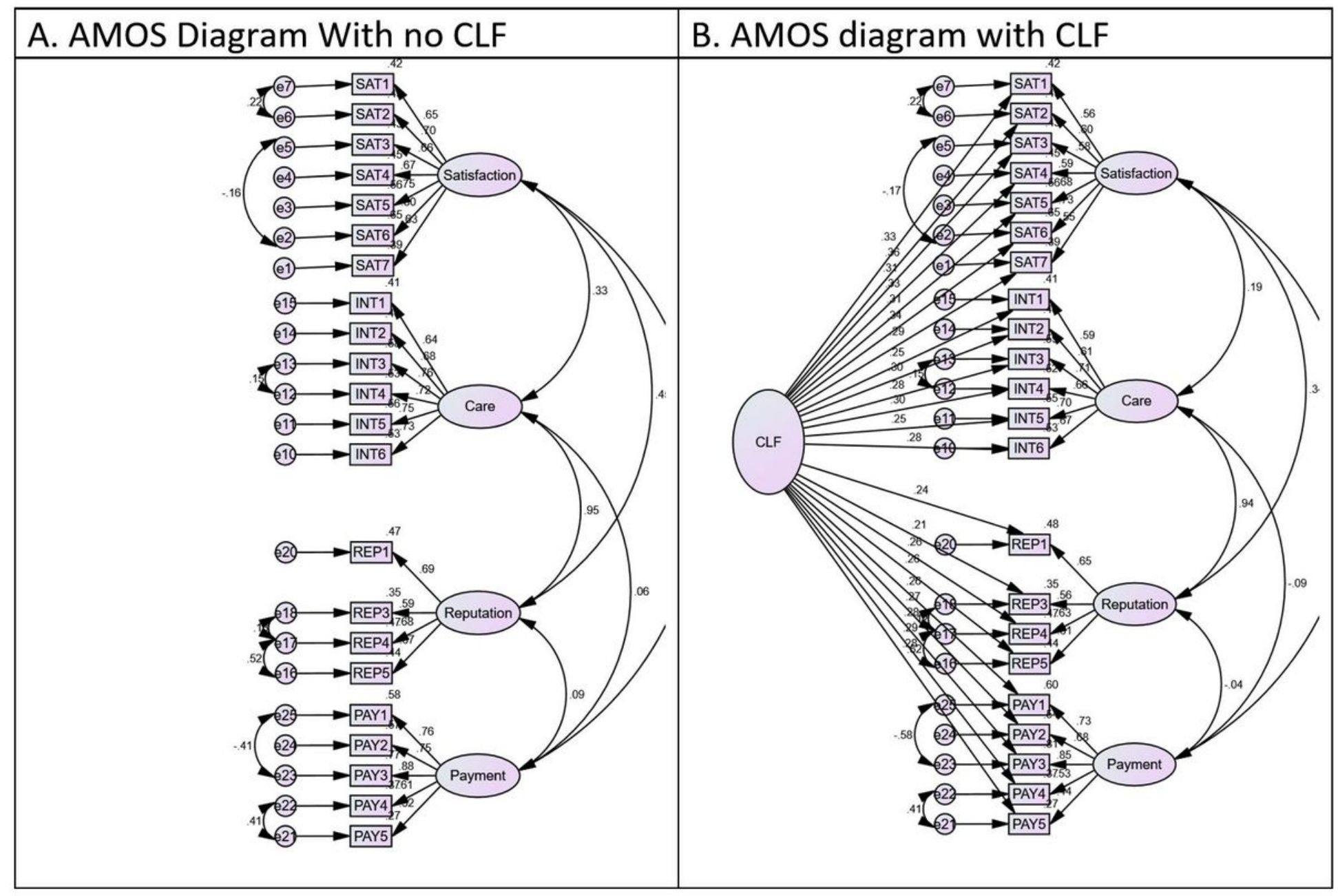

Figure 2

AMOS diagrams for common method bias test; A. With no CLF, B. With CLF. 


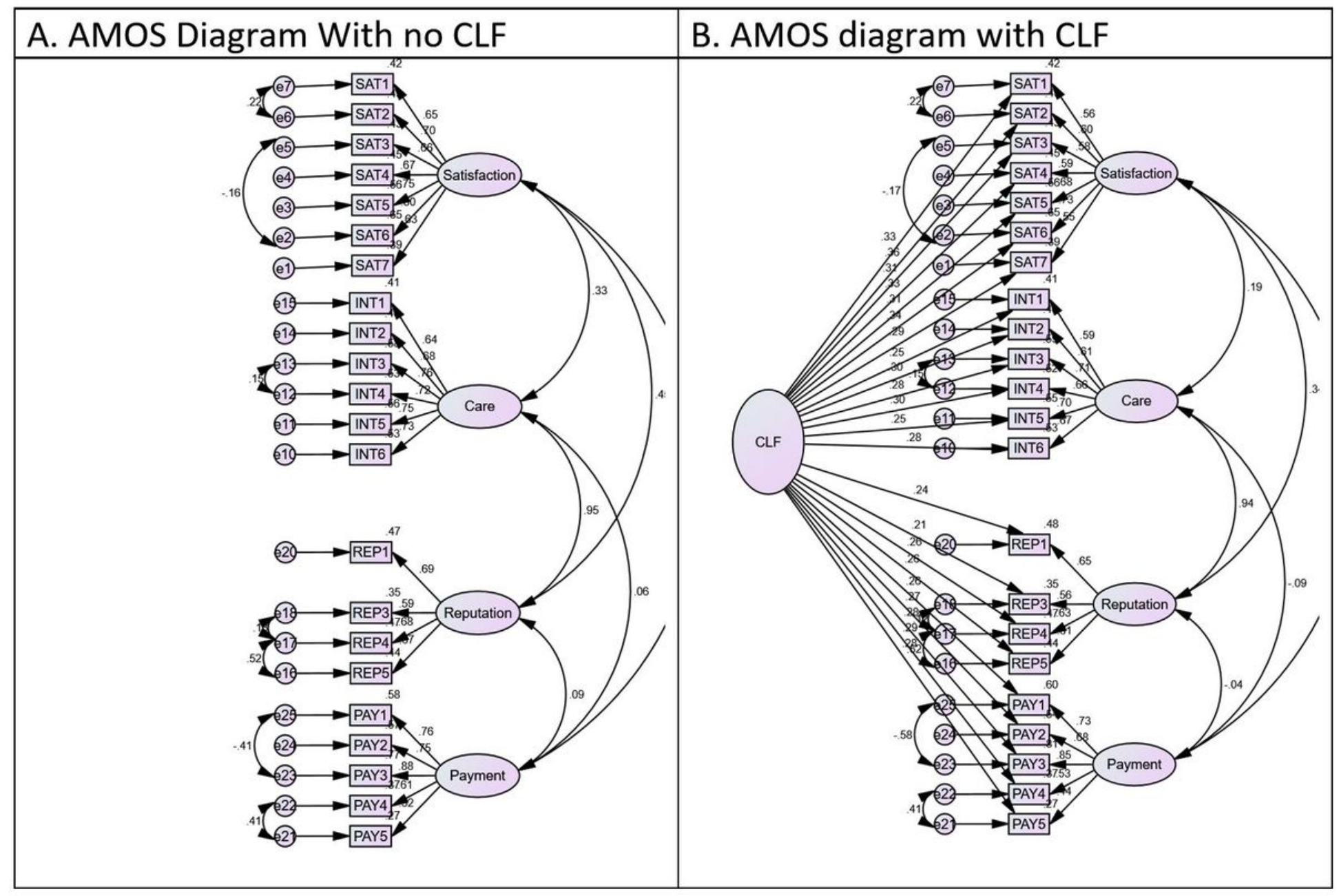

Figure 2

AMOS diagrams for common method bias test; A. With no CLF, B. With CLF. 


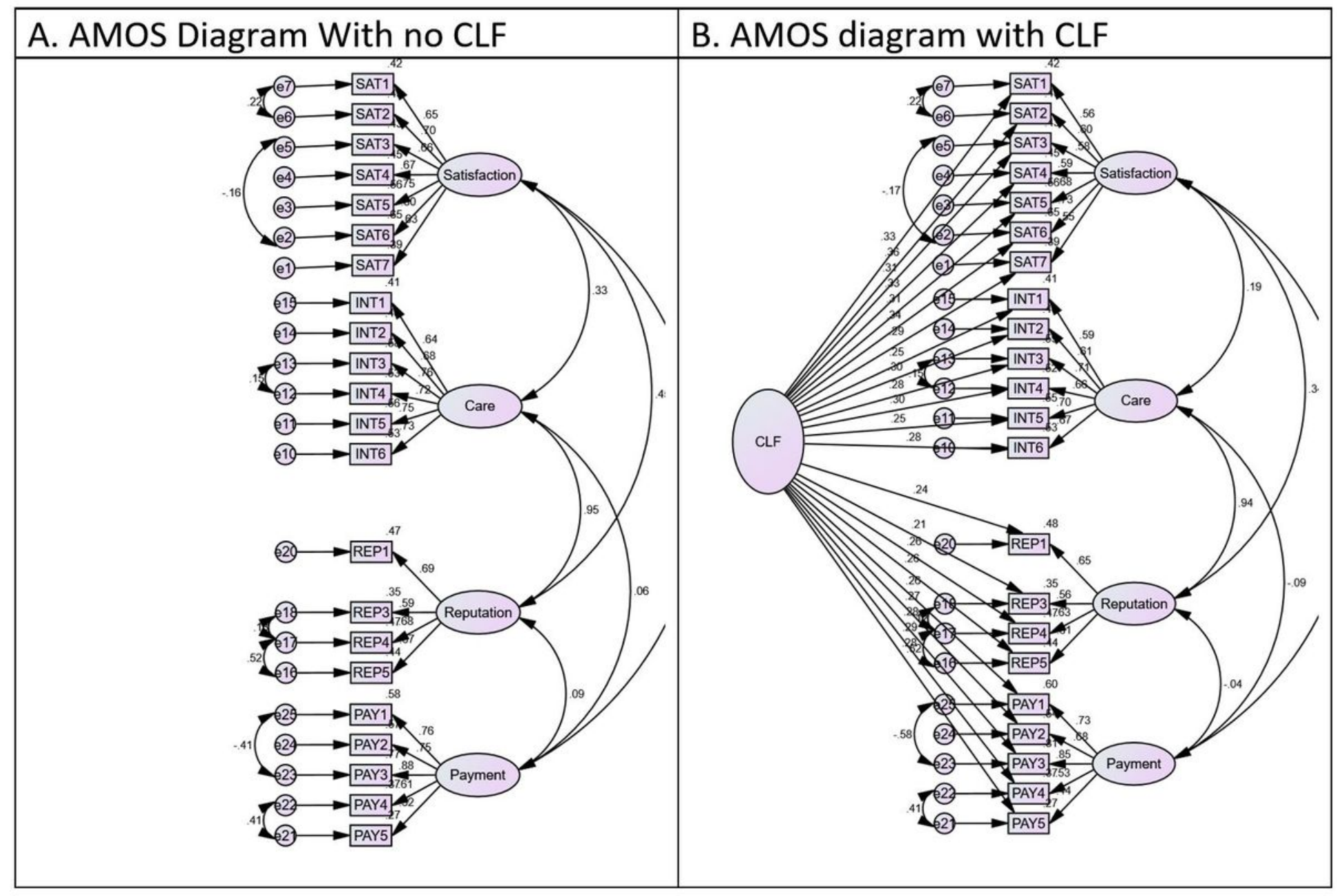

Figure 2

AMOS diagrams for common method bias test; A. With no CLF, B. With CLF.

\section{Supplementary Files}

This is a list of supplementary files associated with this preprint. Click to download.

- DataWuLu1.xlsx

- DataWuLu1.xlsx

- DataWuLu1.xIsx

- questionnaireluwu.doc

- questionnaireluwu.doc

- questionnaireluwu.doc 